\title{
Dedifferentiation of MCF-7 Breast Cancer Continuous Cell Line, Development of Breast Cancer Stem Cells (BCSCs) Enriched Culture and Biomarker Analysis
}

\author{
Ami Ashariati Prayogo ${ }^{1,2, *}$, Andi Yasmin Wijaya ${ }^{2,3}$, Winona May Hendrata ${ }^{2,3}$, \\ Steven Sheng Looi ${ }^{4}$, Reny I'tishom ${ }^{5}$, Lukman Hakim²,6, Fedik Abdul Rantam ${ }^{3}$, \\ I Ketut Sudiana ${ }^{7}$, Abdurachman $^{8}$
}

\begin{abstract}
${ }^{1}$ Hematology-Medical Oncology Division, Department of Internal Medicine, Dr. Soetomo Teaching Hospital, Jl. Mayjen Prof. Dr. Moestopo No.6-8, Surabaya, Indonesia

${ }^{2}$ Faculty of Medicine, Universitas Airlangga, Jl. Mayjen Prof. Dr. Moestopo No.47, Surabaya, Indonesia

Stem Cell Research and Development Center, Universitas Airlangga, Jl. Mayjen Prof. Dr. Moestopo No.47, Surabaya, Indonesia ${ }^{4}$ School of Medicine, National University of Ireland Galway, University Road, Galway, Ireland

${ }^{5}$ Department of Biomedicine, Faculty of Medicine, Universitas Airlangga, Jl. Mayjen Prof. Dr. Moestopo No.47, Surabaya, Indonesia ${ }^{6}$ Urology-Oncology Division, Department of Urology, Dr. Soetomo Teaching Hospital, Jl. Mayjen Prof. Dr. Moestopo No.6-8, Surabaya, Indonesia ${ }^{7}$ Department of Pathological Anatomy, Faculty of Medicine, Universitas Airlangga, Jl. Mayjen Prof. Dr. Moestopo No.47, Surabaya, Indonesia

${ }^{8}$ Department of Anatomy and Histology, Faculty of Medicine, Universitas Airlangga, Jl. Mayjen Prof. Dr. Moestopo No.47, Surabaya, Indonesia
\end{abstract}

*Corresponding author. E-mail: amiashariati@yahoo.com

Received date: Sep 5, 2019; Revised date: Mar 10, 2020; Accepted date: Mar 11, 2020

\section{Abstract}

B ACKGROUND: Cancer stem cells (CSCs) eradication might serve as a robust approach for cancer eradication. MCF-7 as breast cancer continuous cell line is known to contain breast CSCs (BCSCs) for its capability to maintain its original tumor population. CSCs enriched culture is a fundamental tool for CSCs targeted therapy development. Effective and unsophisticated CSCs dedifferentiation protocol for producing CSCs enriched culture is needed.

METHODS: MCF-7 cells were cultured initially in Dulbecco's Modified Eagle Medium (DMEM) low glucose medium then changed to DMEM:F12. Serum starvation was performed during each medium refreshment gradually with fetal bovine serum (FBS) concentration of $10 \%, 5 \%, 2.5 \%$ until reaching $1 \%$ FBS concentration. Stable MCF-7 culture was then adapted to serum free culture system, containing DMEM:F12, epidermal growth factor (EGF), basic fibroblast growth factor (bFGF), and B27 supplement as dedifferentiation protocol for 18 days. Cluster of differentiation (CD) 44 and CD24 double staining immunocytochemistry was performed to evaluate cell stemness.

RESULTS: The population of cells expressing BCSCs markers $\left(\mathrm{CD}_{4} 4^{+} / \mathrm{CD} 24^{\text {low }}\right)$ in non-adherent single cells subpopulation was significantly increased after the dedifferentiation procedure $(70.39 \%)$ compared to control groups $(0.71 \%)(p<0.05)$. In contrast, the expression of BCSCs marker in adherent single cells subpopulation and for both adherent and non-adherent mammosphere the BCSCs markers showed a stable expression.

CONCLUSION: BCSCs enrichment of breast cancer cell cultures from MCF-7 breast cancer cell line can be performed. Breast cancer cell plasticity is observed during the dedifferentiation protocol. Development of dedifferentiation inducing protocols can serve as an important foundation for breast cancer therapy development through BCSCs elimination.

KEYWORDS: breast neoplasms, cell line, dedifferentiation, immunohistochemistry, neoplastic stem cells

Indones Biomed J. 2020; 12(2): 115-23 


\section{Introduction}

Breast cancer is still the highest incident of malignancy among female which encompasses $24.2 \%$ of all female cancer and is responsible for $15 \%$ of mortality rate worldwide.(1) The world burden of cancer is also estimated to increase annually.(2) Breast cancer therapeutic strategy such as surgery, chemotherapy, and radiotherapy are well known for their curative ability, but the risk of relapse still exists.(3) Current cancer therapy mainly focuses on achieving remission status, however cancer could covertly progress, resulting in relapse.(4) Relapsed cancers often progress rapidly and have a worse prognosis.(5) Recent findings suggest that cancer stem cells (CSCs) play an important role in cancer relapse.(6)

CSCs is a distinct tumor cell type which exhibit stem cells-like phenotype.(7) CSCs possess the ability to self-renew and differentiate, leading to the formation of a heterogeneous cancer cell population.(8) CSCs are also resistant to chemotherapy and radiotherapy, resembling normal stem cells.(9) Targeting CSCs could potentially end the prolonged war against cancer.(10) CSCs are known to exist in both solid and non-solid cancers, it was first identified in acute myeloid leukemia (AML) (11) and then in solid tumor (12). The most reliable method of identifying CSCs are by assessing their tumorigenic properties through inoculation into immunocompromised animals, yet the usage of animal models have several disadvantages.(13) Therefore studies on identification of CSCs biomolecular markers were conducted, which eventually yielded a particular marker expressed by CSCs.(14) CSCs marker differ in each cancer source, cluster of differentiation (CD)44, CD24, and aldehyde dehydrogenase 1 (ALDH1) are expressed in breast cancers, whereas CD34 and CD38 are expressed in AML.(11,12,15) Understanding the biology of CSCs is important for developing an eradication strategy. In recent developments, CSCs studies have shown that asymmetric mitosis and cell dedifferentiation have a pivotal role in maintaining the pool of CSCs and cancer hierarchical population composition.

The concept of dedifferentiation is the ability to reverse the cellular clock.(16) This concept was proven by the production of induced pluripotent stem cells (iPSCs). iPSCs are differentiated cells which were reprogrammed by induction with several growth factors (Oct4, Sox2, Klf4, and c-Myc).(17) In this study, terminally differentiated fibroblasts were able to revert back to their pluripotent state, an ability originally only possessed by embryonic stem cells (ESC).(18) Pluripotency of both iPSCs and ESC grant these cells the capability to differentiate into any type of cell which construct the body.(19) Pluripotent cells will undergo the differentiation process and transform into specific stem cells with less differentiation capaability or multipotent stem cells (MSC).(20) MSC could differentiate into specific ectoderm, mesoderm, or endoderm cell types. (20) Oligopotent stem cells from MSC lineage have more limited differentiation potential and eventually produce specific mature unipotent stem cells which only have the ability to produce specific differentiated cells.(13) For instance, neural progenitor cells only have the ability to produce neuronal cells and are unable to produce cells of a blood cell lineage.(20) Terminally differentiated cells then undergo the processes of a normal cell and will eventually suffer from cell aging and cell death.

The stem cell population pool is maintained by asymmetric mitosis, which differs from regular mitosis because it produces two non-identical daughter cells, stem cells with original stemness ability (self-renewing stem cells) and stem cells with limited differentiation ability.(21) Asymmetric mitosis, differentiation, and dedifferentiation mechanism also present in CSCs.(22).

Established continuous cell lines are one example of a platform for in vitro studies involving cancer biology. Cancer cell line immortality and its ability to overcome the Hayflick limit (23), which limits cell division ability are consistent with the concept of CSCs (7), based on this fact it is concluded that CSCs are present among the cancer cell population. One of the breast cancer cell line is MCF-7, which originated from luminal-A breast cancer. (24) Dedifferentiation of cancer cell lines by growth factors administration in growth factors supplemented serum free condition may produce CSC-enriched cultures that will serve as a basis for understanding CSC biology and the development of CSC targeted therapy.

\section{Methods}

This study had been approved by the Health Research Ethic Committee of Faculty of Medicine, Universitas Airlangga , Surabaya (Ethical Clearance No. 48/EC/KEPK/ FKUA/2018).

\section{Cell Culture}

MCF-7 (ATCC) human breast cancer continuous cell lines were obtained from the Cancer Chemopreventive Research Center, Universitas Gadjah Mada Yogyakarta, Indonesia. 
MCF-7 cells were maintained in Dulbecco's Modified Eagle Medium (DMEM) low glucose medium (Gibco, New York, USA) with $10 \%$ fetal bovine serum (FBS) (Gibco) at $37^{\circ} \mathrm{C}$, in a $5 \% \mathrm{CO}_{2}$ saturated humidified cell culture incubator.

\section{Serum Starvation Procedure}

Confluent MCF-7 cells were passaged and the initial medium was replaced with DMEM:F12 (Gibco) with 10\% FBS. Confluent cultures were passaged and prepared to undergo serum starvation. Serum starvation was performed by refreshing the culture medium every three days, with serum concentration of $10 \%, 5 \%, 2.5 \%$, and $1 \%$ before underwent dedifferentiation process with dedifferentiation medium. MCF-7 serum starved cells were cultured until up to $80 \%$ confluence and cultured into two 24 -well culture plate with sterile coverslips. The cells were divided into 7 groups, which consist of 1 control group and 6 groups for the harvesting in the $3^{\text {th }}, 6^{\text {th }}, 9^{\text {th }}, 12^{\text {th }}, 15^{\text {th }}$, and $18^{\text {th }}$ day as a treatment group. Each group was quadruplicated $(n=4)$.

\section{BCSCs Dedifferentiation Process}

Treatment group which previously cultured on DMEM:F12 with $1 \%$ FBS then underwent medium change to dedifferentiation serum free medium, which composed of serum free DMEM:F12, human epidermal growth factors (EGF) (Biolegend, San Diego, California, USA), human basic fibroblast growth factor (bFGF) (Biolegend), and B27 supplemented medium (Gibco).(25) The dedifferentiation process was carried out for 18 days, with dedifferentiation medium being changed every 3 days. During medium refreshment, morphological observations were done using an inverted microscope (Olympus, Tokyo, Japan). Due to the emergence of adherent and non-adherent cells population, the methods of cells retrieved were different. Adherent cells were directly harvested from the coverslip and fixated with 10\% neutral buffer formalin (Merck, Kenilworth, New Jersey, USA). Non-adherent cells were collected from the culture medium, centrifuged fixated with $10 \%$ neutral buffer formalin (Merck), recentrifuged and retrieved from the pellet. Cells were collected and fixated for the control group on the $0^{\text {th }}$ days and on the $3^{\text {th }}, 6^{\text {th }}, 9^{\text {th }}, 12^{\text {th }}, 15^{\text {th }}$, and $18^{\text {th }}$ day for the treatment group $(n=4)$.

\section{Breast Cancer Stem Cell Marker Detection}

Adherent cells were prepared by sticking coverslips with its adherent cells on glass slides. Non-adherent cells, which originated from centrifuged medium pellets were fixated and smeared on poly-L-lysine coated glass slides (Muto Pure Chemicals, Tokyo, Japan), and dried in a biosafety cabinet overnight. The fixated cells then undergo cell permeabilization which was carried out by incubation with $0.02 \%$ IGEPAL CA-630 (Sigma-Aldrich, St. Louis, Missouri, USA) for 7 minutes before the immunocytochemistry staining procedure was performed. (26) CD44 and CD24 double stain immunocytochemistry were performed using anti-human CD44 monoclonal antibody (ABCAM, Cambridge, UK), anti-human CD24 monoclonal antibody (ABCAM), and Lab Vision ${ }^{\mathrm{TM}}$ MultiVision Polymer Detection System double staining kit (ThermoFisher Scientific, Waltham, Massachusetts, USA).

Double stain immunocytochemistry staining was performed according to the kit manufacturer's protocol. After permeabilization protocols the blocking process was carried out. Blocking solution, which was Ultra V Block and Lab Vision ${ }^{\mathrm{TM}}$ Hydrogen Peroxidase Block which included in Lab Vision ${ }^{\mathrm{TM}}$ MultiVision Polymer Detection System kit by incubation for 5 minutes at $37^{\circ} \mathrm{C}$ temperature (ThermoFisher Scientific). Solely administration of MultiVision anti-rabbit/AP + anti-mouse/HRP polymer (cocktail) without primary antibody were used as control. LVRed and LVBlue Chromogen were utilized to visualized immunostaining for 10 minutes. Weak counterstain with Harris haematoxylin (Merck) was used to stain cell nuclei by incubating for 10 seconds. Immunocytochemistry stained cells were then observed under a Leica DM750 light microscope (Leica, Wetzlar, Germany).

\section{Immunocytochemistry Interpretation}

Expression of CD24 on the cells is represented by the red-brown colour of the cells, and blue colour indicates the expression of CD44 marker. The cells were grouped into two groups of observation: mammosphere and single cell population. Based on CD44/CD24 expression, the cells were divided into 5 groups (CD44-/CD24+, CD $44^{+} /$ $\mathrm{CD} 24^{\text {low }}, \mathrm{CD}_{4} 4^{+} / \mathrm{CD} 24^{\text {medium }}, \mathrm{CD} 44^{+} / \mathrm{CD} 24^{\text {high }}$, and $\mathrm{CD} 44^{+} /$ CD24). BCSCs quantification and the measurement of population percentage were utilized to evaluate the degree of dedifferentiation and the distribution of cell phenotype based on the BCSCs marker expression. $(27,28)$ Divided observation of single cells and mammosphere population were done for both adherent and non-adherent populations by two independent pathologist (Figure 1, Figure 2).

\section{Statistical Analysis}

Kruskall-Wallis's analysis with SPSS ver 24 (IBM Coorporation, New York, USA) was performed to evaluate BCSCs marker expression difference for adherent and nonadherent cells in single cell and mammosphere populations. 


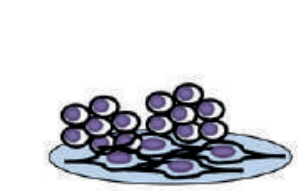

Adherent cells on coverslip
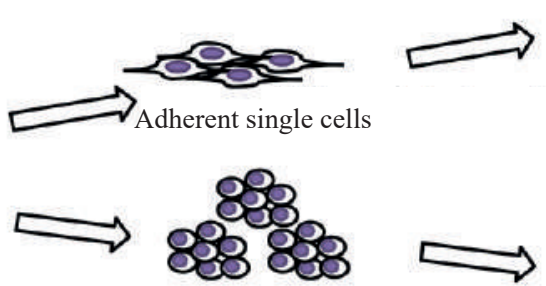

Adherent mammosphere
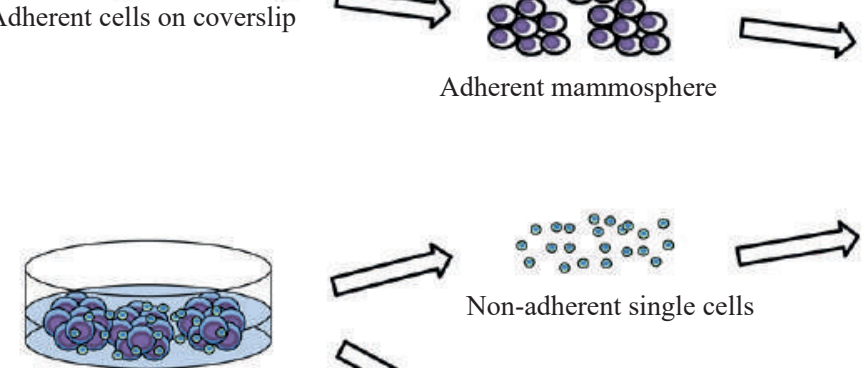

Non-adherent cells on culture supernatant
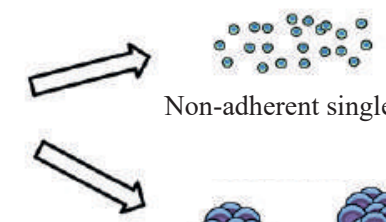

Non-adherent single cells

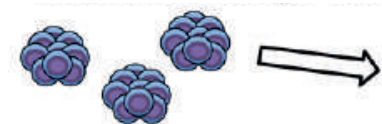

Non-adherent mammosphere

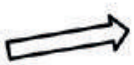

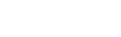
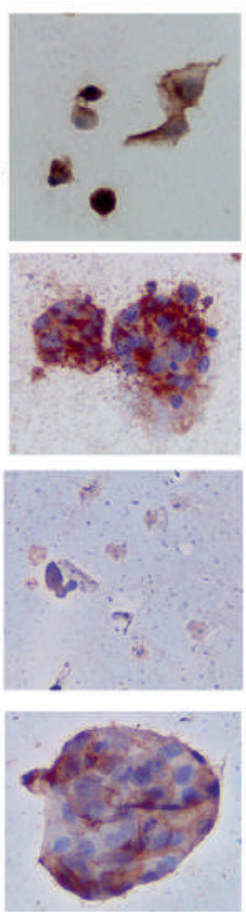

Figure 1. Workflow of molecular marker expression interpretation.

\section{Results}

\section{Morphological Change}

Epithelial-mesenchymal transition (EMT) was the change of cell morphology and characteristics that occurs in epithelial cells. This change could cause epithelial cell phenotypes to change into mesenchymal cells, while the reverse mechanism, which changed mesenchymal cell phenotypes into epithelial phenotypes was called mesenchymal to epithelial transition (MET). Epithelial cells were usually present in glands and the surface of organs, which tend to be stationary and have a limited ability of migration. On the other hand, mesenchymal cell types were mainly present in the stroma of organs with good mobility and dynamic adaptability. In stem cell biology, the process of EMT explains the activation and homing ability of stem cells. EMT was a dynamic process, which occurred ubiquitously in the organism, and a miss in EMT might result in grave consequences.

The initial MCF-7 cell line morphology was squamous cells with hexagonal-shaped membranes could be observed in the control groups both in before or after the serum starvation procedure (Figure 3 ). On the $3^{\text {rd }}$ day of dedifferentiation protocol, MCF-7 morphology gradually changed from squamous into a round-shaped form, aggregated and began to form anchored cauliflower-like structures (Figure 3). Dedifferentiation of MCF-7 yielded two different populations on the $6^{\text {th }}$ day: adherent and nonadherent populations. Mammosphere was the formation of
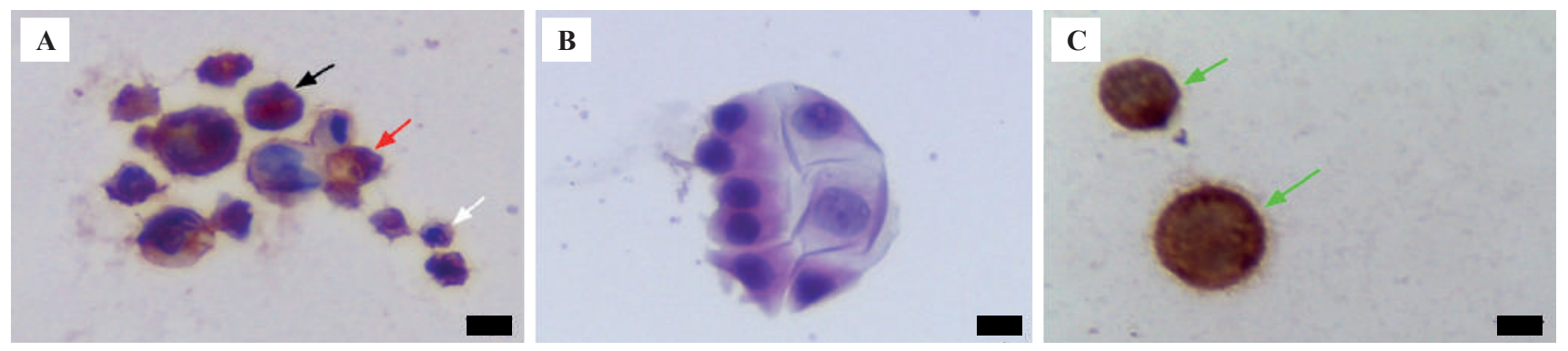

Figure 2. Grouping of cells phenotype based on marker expression. A: CD $24^{\text {low }} / \mathrm{CD} 44^{+}$(white arrow), CD24 ${ }^{\text {medium}} / \mathrm{CD} 44^{+}$(red arrow) and $\mathrm{CD} 24^{\text {high }} / \mathrm{CD} 44^{+}$(black arrow) cells on the $18^{\text {th }}$ days of dedifferentiation; B: Haematoxylin-Eosin staining on the $18^{\text {th }}$ days of dedifferentiation; $\mathrm{C}$ : CD24+CD44- cells (green arrow) on the $12^{\text {th }}$ days of dedifferentiation. Black bar: $10 \mu \mathrm{m}$. 

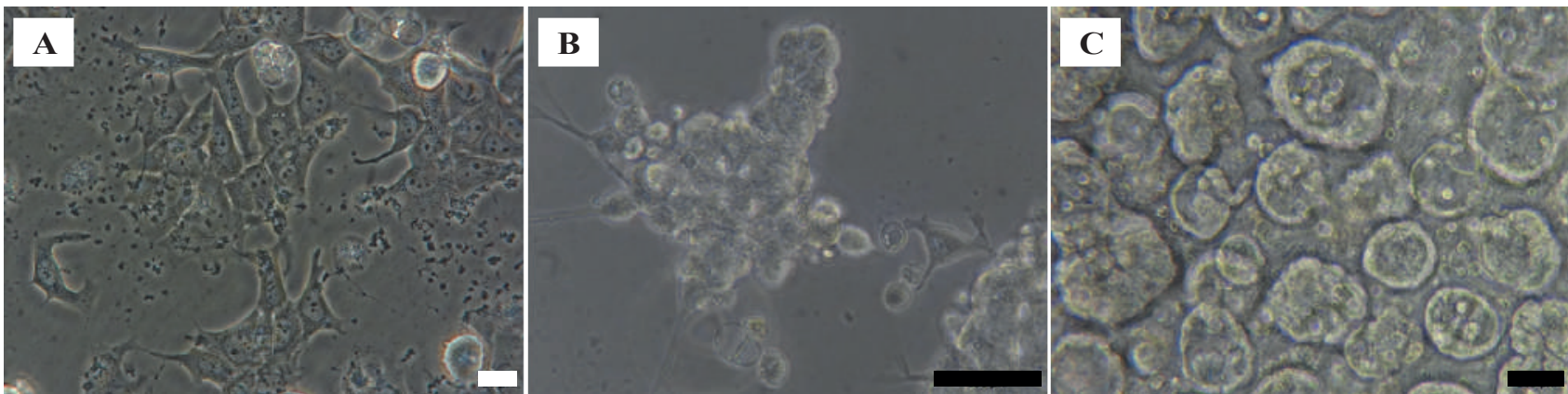

Figure 3. Squamous cell appearance, cauliflower-like morphological change, and non-adherent cells formation. A: Adherent squamous cells with epithelial likes phenotype MCF-7 morphology on control group (D-0); B: Adherent cauliflower-like structure, lost of adherence, EMT-like process on the $3^{\text {th }}$ days of dedifferentiation; C: Mammospheres formation on the $18^{\text {th }}$ days of dedifferentiation. White bar: $10 \mu \mathrm{m}$; Black bar: $100 \mu \mathrm{m}$.

spherical structure consisted of breast cells which could be observed beginning in the $3^{\text {rd }}$ day. Detached cells and mammosphere from the cauliflower-like structure gave rise to the non-adherent population (Figure 1, Figure 2, Figure $3)$. Mammosphere growth and multiplication occurred on the $6^{\text {th }}, 9^{\text {th }}, 12^{\text {th }}, 15^{\text {th }}$, and $18^{\text {th }}$ day of the dedifferentiation protocol.

Based on the MCF-7 morphological change during the dedifferentiation protocol, EMT like process was observed, especially in the first three days of the protocol. Initial
MCF-7 squamous morphology, which was closely related to epithelial phenotype gradually began to changed into a rounder cell shape and lost its original epithelial appearance (Figure 3, with serial labeling in Figure 4 and Figure 5). This process might be closely related to the mechanism of metastasis, making it a vital process in cancer biology. This finding suggests that this dedifferentiation protocol might be utilized to obtain a closer look into the EMT process by performing a specific EMT related marker and assays.
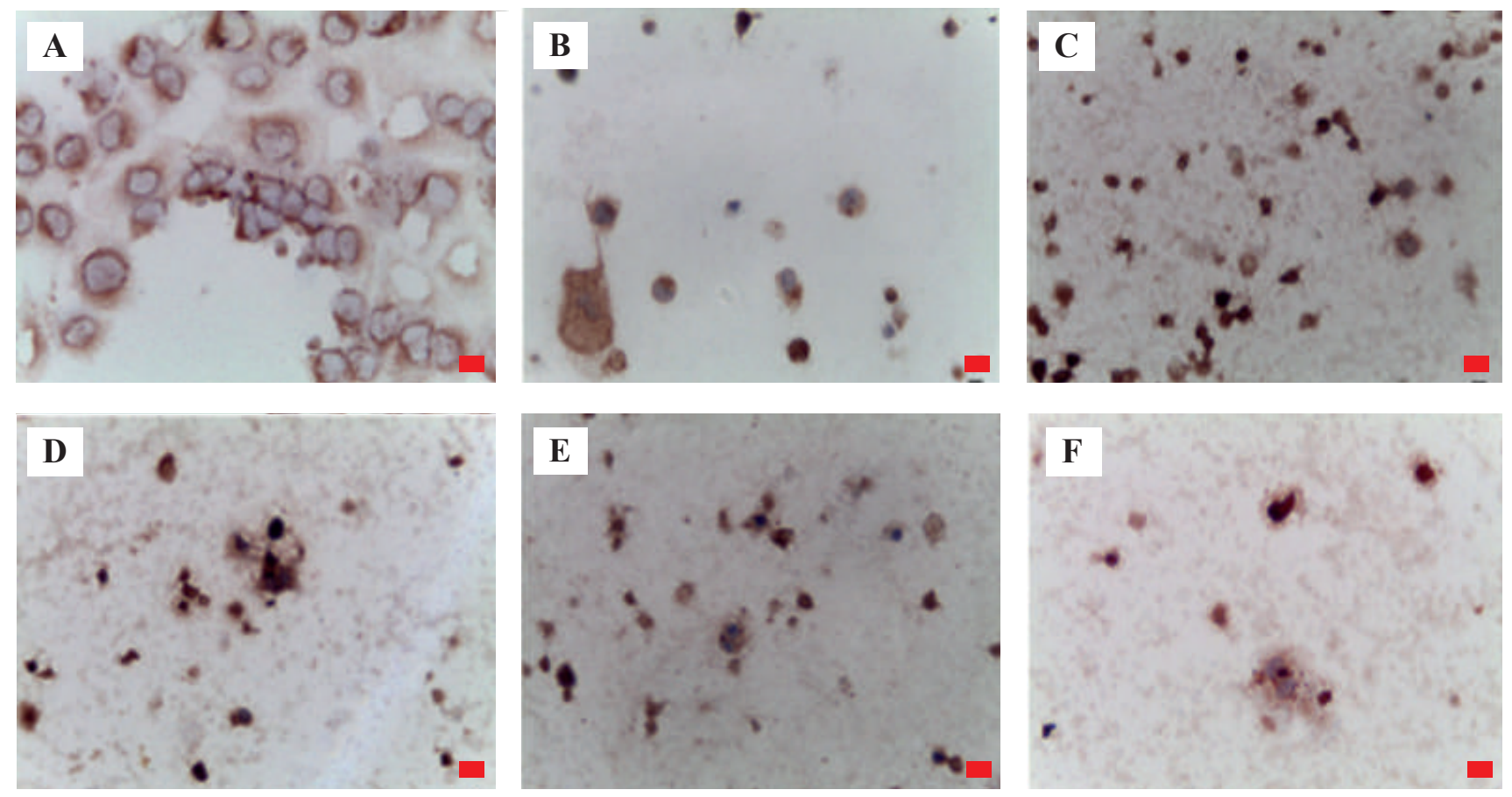

Figure 4. Serial staining of cells during culture in dedifferentiation inducing medium in the adherent population. A: Adherent cells on the $3^{\text {rd }}$ days observation; B: Adherent cells on the $6^{\text {th }}$ days observation; C: Adherent cells on the $9^{\text {th }}$ days observation; D: Adherent cells on the $12^{\text {th }}$ days observation; E: Adherent cells on the $15^{\text {th }}$ days observation; F: Adherent cells on the $18^{\text {th }}$ days observation. CD24/CD44 double staining, Red bar: $10 \mu \mathrm{m}$. 

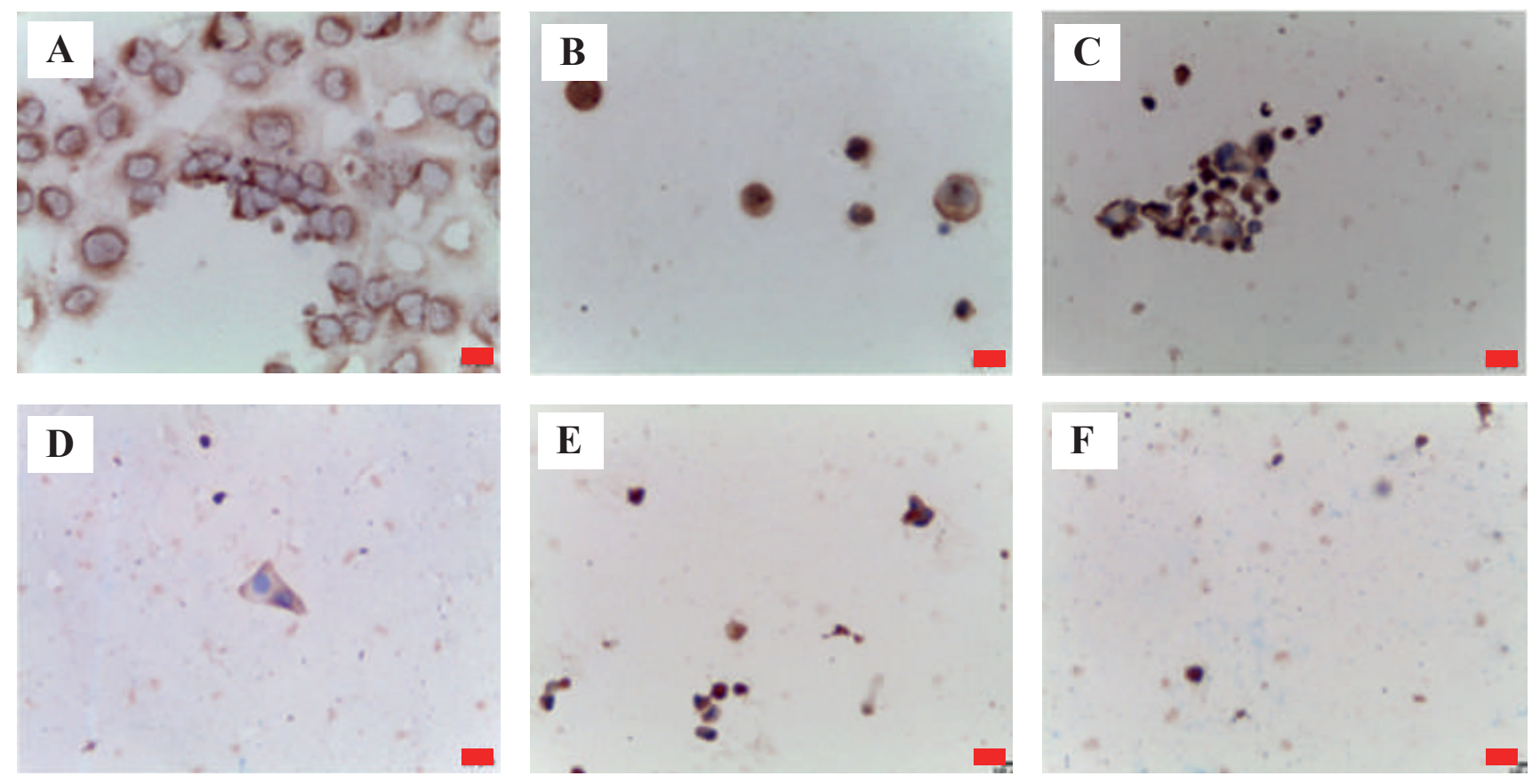

Figure 5. Serial staining of cells during culture in dedifferentiation inducing medium in the non-adherent population. A: Nonadherent cells on the $3^{\text {rd }}$ days observation; B: Non-adherent cells on the $6^{\text {th }}$ days observation; C: Non-adherent cells on the $9^{\text {th }}$ days observation; D: Non-adherent cells on the $12^{\text {th }}$ days observation; E: Non-adherent cells on the $15^{\text {th }}$ days observation; F: Non-adherent cells on the $18^{\text {th }}$ days observation. CD24/CD44 double staining, Red bar: $10 \mu \mathrm{m}$.

\section{CD44 and CD24 Expression Profile Difference in The Single Cell Population}

CD24 marker was indicated by the appearance of redbrownish colour, while CD44 marker was marked by blue colour. Based on the intensity of colour, intensity of CD24 expression is graded as high, medium or low expressing cells, while a faint colour was only able to distinguish between expressing and non-expressing cells.

Disseminated single cells of the enriched MCF-7 CSCs culture could be detected in both the adherent and non-adherent cells population beginning from the $6^{\text {th }}$ day of dedifferentiation protocol (Table 1, Table 2) The initial population of MCF-7 breast cancer cell lines exhibited an immense surface expression of CD24, yet CD44 expression was barely detectable. High levels of CD24 expression and limited expression of CD44 in the initial MCF-7 population suggested that it contained breast cancer cells with a high degree of differentiation. The initial MCF-7 monolayer culture was dominated with $\mathrm{CD} 24^{+} / \mathrm{CD} 44^{-}$cells, which showed a high degree of breast cancer differentiation. Detection of CD44 expression increased along the course of dedifferentiation protocols mainly in the non-adherent subpopulation (Table 2). Observation of population cell dynamics in the adherent population began from the $3^{\text {rd }}$ day, with a notable gradual growth of the CD24 $4^{\text {medium/ }}$
CD44 $4^{+}$population and decreasing levels of CD24 $4^{\text {low }} / \mathrm{CD} 44^{+}$ population. The trend of $\mathrm{CD} 24^{\text {high }} / \mathrm{CD} 44^{+}$cell stabilized during the dedifferentiation protocol and peaked on the $12^{\text {th }}$ day. This results suggest that the subpopulation of nonadherent single cells was dominated by the CD24 $4^{\text {low }} / \mathrm{CD} 44^{+}$ at the end of culture in dedifferentiation medium, yet the adherent single cells exhibit a more maturation phenotype.

\section{Difference in CD44 and CD24 Expression Profiles in The Mammosphere Population}

MCF-7 mammospheres from the CSC-enriched culture were observed in the form of non- adherent and adherent population. Non-adherent mammosphere were observed from the $6^{\text {th }}$ day, and on the $12^{\text {th }}$ day the adherent mammosphere was identified (Table 2, Figure 4, Figure 5).

CD24 expression as a marker of breast cancer differentiation was prominently observed in the adherent mammosphere and CD44 expression as a breast cancer stemness marker was more prominent in the non-adherent mammosphere. However, compared to the non-adherent single cell population, the CSCs markers were less prominent in the mammosphere population (Table 1, Table 2).

From the $6^{\text {th }}$ day, CD24 $4^{\text {medium }} / \mathrm{CD} 44^{+}$cells dominated the non-adherent mammosphere. Conversely in the adherent mammosphere population, the differentiate 

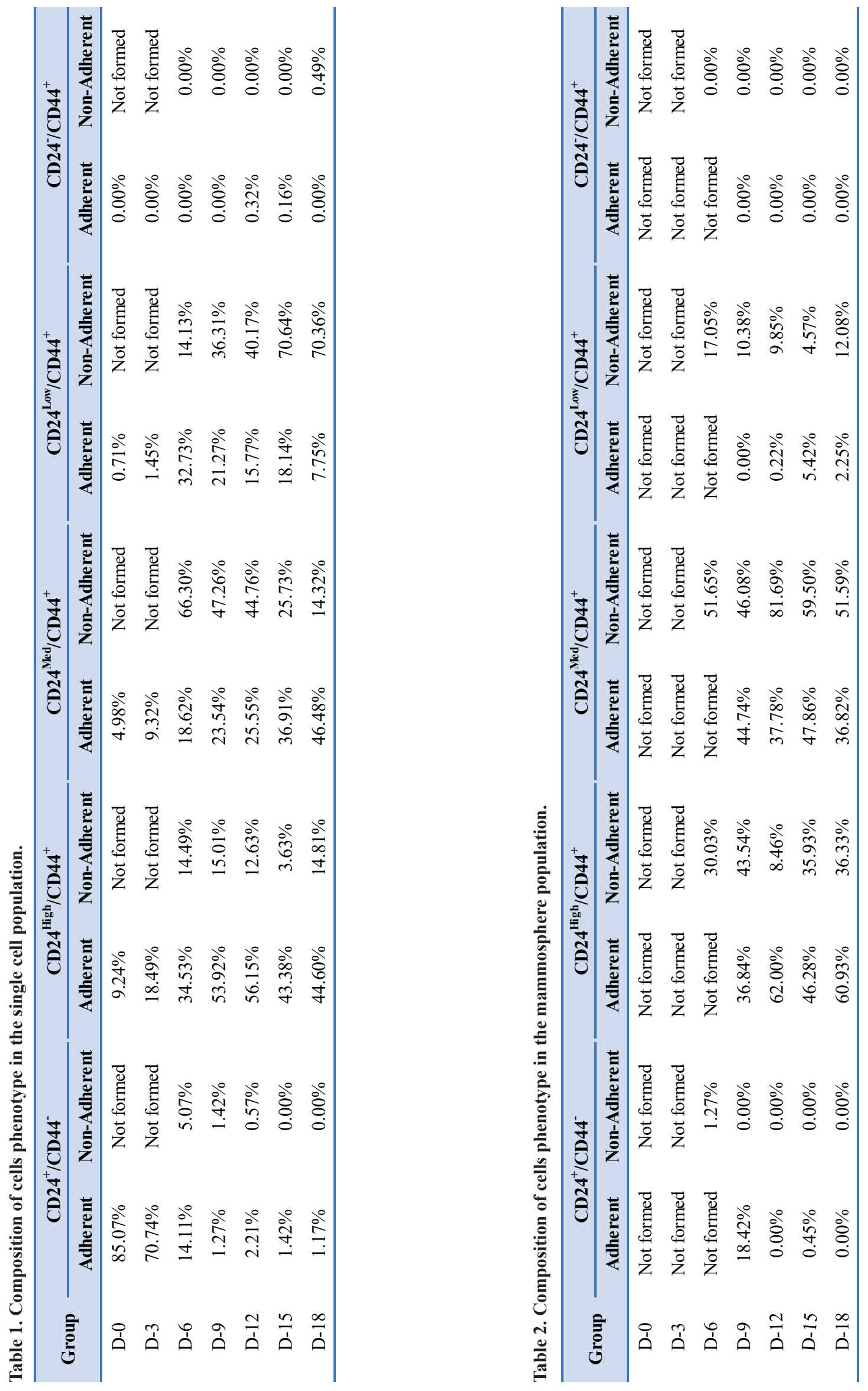
$\mathrm{CD} 24^{\text {high }} / \mathrm{CD} 44^{+}$cells were dominating from the $12^{\text {th }}$ day of the dedifferentiation protocol until the $18^{\text {th }}$ day. The rising percentage of $\mathrm{CD} 24^{\mathrm{low}} / \mathrm{CD} 44^{+}$cells, which occurred in the non-adherent mammosphere in line with the dedifferentiation protocols duration, was observed in the non-adherent mammosphere populations (Table 2)

\section{Discussion}

\section{Dedifferentiation Signaling}

Cancer dedifferentiation is tightly linked with inflammation, hypoxia, and response to cellular damage.(29) These pathways of cellular dedifferentiation eventually cross in hypoxia-inducible factors (HIF)- $1 \alpha$ and HIF-2 $\alpha$ signaling. HIF- $1 \alpha$ and HIF- $2 \alpha$ are peculiar protein which are usually degraded in normoxic conditions, but maintained in hypoxic conditions.(30) HIF-1 $\alpha$ and HIF-2 $\alpha$ translocate into the nucleus, binding with HIF-1 $\beta$ to form a protein complex which goes into DNA hypoxia response element (HRE) and triggers transcription of complex cellular signaling molecules of hypoxia response and cell dedifferentiation. $(31,32)$

EGF and bFGF which are present in the inflammation and cellular damage response could mimic hypoxic signaling conditions and arrest the HIF- $1 \alpha$ and HIF- $2 \alpha$ degradation process, which eventually triggers cellular dedifferentiation. (32-34) This method could possibly produce CSCs by dedifferentiating malignant cells. In the in vitro setting the supplementation of EGF and bFGF to the serum free medium could mimic this in vivo process and yield a CSCenriched culture.

\section{Expression of BCSC Markers}

BCSC marker detection using immunocytochemistry is one of the techniques able to detect the presence of CSCs in the heterogeneous cell line population. Expression of CD44 is thought to be a stemness marker whereas CD24 acts as a marker of differentiation in breast CSCs.(15) Utilization of simultaneous detection of CD24 and CD44 in double staining immunocytochemistry allows $\mathrm{CD} 44^{+} / \mathrm{CD} 24^{- \text {/low }}$ cells which are thought to be BCSCs to be distinguished from the rest of the population. Elevated levels of CD44 expression and low CD24 expression could determine the success of dedifferentiation protocols (15), yet the dedifferentiation protocols reveal 4 distinct subpopulation of cells inside MCF-7 breast cancer cell line population. The 4 subgroups are distinguished based on cell adherence and cell morphology as a single cell or mammosphere forming population. BCSC marker expression from the 4 subgroups varies from each other, but the main difference is that the adherent population tends to express higher amounts of differentiation markers than the non-adherent population. However, the mammosphere forming subpopulation showed domination of $\mathrm{CD} 24^{\text {medium }} / \mathrm{CD} 44^{+}$cells which have a moderate level of differentiation degree between the CSCs and differentiate cancer cells. These results suggest that the 4 distinct subpopulation of cancer cells identified in this study could be present in every cancer cell population, hinting that the theory of an existence of a lineage of cancer cell population from CSCs could be proven. Nevertheless, future studies should utilize an in vivo assay for assessing cell tumorigenicity to determine how these subpopulations differ in their ability to cause cancer. Confirmation of a cell's ability to dedifferentiate and give rise to an original MCF-7 cells population should also be performed. Isolation of each respective subpopulation and culturing them in serum supplemented medium could be performed to assess the differentiation capability of each subpopulation. Further confirmation by other quantitative techniques such as flowcytometry is also encouraged.

\section{Clinical Implication}

Development of BCSC-enriched cultures from breast cancer continuous cell lines could serve as the platform for the development of CSC targeted therapy and provide a deeper understanding of CSC biology.(7) In the clinical setting, development of CSC targeted therapy, especially with regards to breast cancer treatment could hopefully plummet the number of relapsing cancer cases and provide a novel approach to cancer therapy. In the future, CSC targeted therapy could replace the use of costly and hazardous cytostatic agents in current chemotherapy regimens as well as decreasing the potential side effects of radiotherapy.

\section{Conclusion}

Development of BCSC-enriched cultures from MCF-7 breast cancer continuous cell lines could be performed by utilizing serum-free medium supplemented by EGF, bFGF and B27 supplement medium. BCSCs-enrichment was completed by reprogramming breast cancer cell lines to undergo a dedifferentiation process through hypoxia response related pathways. 


\section{References}

1. Bray F, Ferlay J, Soerjomataram I, Siegel RL, Torre LA, Jemal A. Global cancer statistics 2018: GLOBOCAN estimates of incidence and mortality worldwide for 36 cancers in 185 countries. CA Cancer J Clin. 2018; 68: 394-424.

2. Prager GW, Braga S, Bystricky B, Qvortrup C, Criscitiello C, Esin $\mathrm{E}$, et al. Global cancer control: Responding to the growing burden, rising costs and inequalities in access. ESMO Open. 2018; 3: e000285. doi: 10.1136/esmoopen-2017-000285.3.

Gerber B, Freund M, Reimer T. Recurrent breast cancer: treatment strategies for maintaining and prolonging good quality of life. Dtsch Arztebl Int. 2010; 107: 85-91.

4. Dragu DL, Necula LG, Bleotu C, Diaconu CC, Chivu-Economescu M. Therapies targeting cancer stem cells: Current trends and future challenges. World J Stem Cells. 2015; 7: 1185-201.

5. Dales JP, Garcia S, Meunier-Carpentier S, Andrac-Meyer L, Haddad $\mathrm{O}$, Lavaut $\mathrm{MN}$, et al. Overexpression of hypoxia-inducible factor HIF- $1 \alpha$ predicts early relapse in breast cancer: Retrospective study in a series of 745 patients. Int J Cancer. 2005; 116: 734-9.

6. Bomken S, Fišer K, Heidenreich O, Vormoor J. Understanding the cancer stem cell. Br J Cancer. 2010; 103: 439-45.

7. Maugeri-Saccà $M$, Bartucci $M$, De Maria R. DNA damage repair pathways in cancer stem cells. Mol Cancer Ther. 2012; 11: 162736.

8. Chen R, Nishimura MC, Bumbaca SM, Kharbanda S, Forrest WF, Kasman IM, et al. A hierarchy of self-renewing tumor-initiating cell types in glioblastoma. Cancer Cell. 2010; 17: 362-75.

9. Abdullah LN, Chow EK-H. Mechanisms of chemoresistance in cancer stem cells. Clin Transl Med. 2013; 2 :3. doi: 10.1186/20011326-2-3.

10. Lou H, Dean M. Targeted therapy for cancer stem cells: the patched pathway and ABC transporters. Oncogene. 2007; 26: 1357-60.

11. Bonnet D, Dick JE. Human acute myeloid leukemia is organized as a hierarchy that originates from a primitive hematopoietic cell. Nat Med. 1997; 3: 730-7.

12. Al-Hajj M, Wicha MS, Benito-Hernandez A, Morrison SJ, Clarke MF. Prospective identification of tumorigenic breast cancer cells. Proc Natl Acad Sci USA. 2003; 100: 3983-8.

13. Hombach-Klonisch S, Panigrahi S, Rashedi I, Seifert A, Alberti $\mathrm{E}$, Pocar P, et al. Adult stem cells and their trans-differentiation potential - perspectives and therapeutic applications. J Mol Med. 2008; 86: 1301-14.

14. Schatton T, Frank NY, Frank MH. Identification and targeting of cancer stem cells. BioEssays. 2009; 31: 1038-49.

15. Ricardo S, Vieira AF, Gerhard R, Leitao D, Pinto R, CameselleTeijeiro JF, et al. Breast cancer stem cell markers CD44, CD24 and ALDH1: expression distribution within intrinsic molecular subtype. J Clin Pathol. 2011; 64: 937-46.

16. Poss KD. Advances in understanding tissue regenerative capacity and mechanisms in animals. Nat Rev Gene. 2010; 11: 710-22.

17. Takahashi K, Yamanaka S. Induction of pluripotent stem cells from mouse embryonic and adult fibroblast cultures by defined factors. Cell. 2006; 126: 663-76.
18. Yamanaka S. Patient-specific pluripotent stem cells become even more accessible. Cell Stem Cell. 2010; 7: 1-2. doi: 10.5772/13969.

19. Khavari DA, Sen GL, Rinn JL. DNA methylation and epigenetic control of cellular differentiation. Cell Cycle. 2010; 9: 3880-3.

20. Bhartiya D, Boheler KR, Rameshwar P. Multipotent to pluripotent properties of adult stem cells. Stem Cells Int. 2013; 2013: 813780 doi: $10.1155 / 2013 / 813780$.

21. Gómez-López S, Lerner RG, Petritsch C. Asymmetric cell division of stem and progenitor cells during homeostasis and cancer. Cell Mol Life Sci. 2014; 71: 575-97.

22. Santoro A, Vlachou T, Carminati M, Pelicci PG, Mapelli M. Molecular mechanisms of asymmetric divisions in mammary stem cells. EMBO Rep. 2016; 17: 1700-20.

23. Hayflick L, Moorhead PS. The serial cultivation of human diploid cell strains. Exp Cell Res. 1961; 25: 585-621.

24. Holliday DL, Speirs V. Choosing the right cell line for breast cancer research. Breast Cancer Res. 2011; 13: 215. doi: 10.1186/bcr2889.

25. Wang J, Liu X, Jiang Z, Li L, Cui Z, Gao Y, et al. A novel method to limit breast cancer stem cells in states of quiescence, proliferation or differentiation: Use of gel stress in combination with stem cell growth factors. Oncol Lett. 2016; 12: 1355-60.

26. Pasternak T, Tietz O, Rapp K, Begheldo M, Nitschke R, Ruperti B, et al. Protocol: An improved and universal procedure for wholemount immunolocalization in plants. Plant Methods. 2015; 11: 50. doi: 10.1186/s13007-015-0094-2.

27. Zhao J, Lin Z, Yao H, Wan Y. Analysis of the relationship between expressions of TF and MMP-9 and prognosis of breast cancer patients. Chinese J Clin Oncol. 2008; 5: 141-5.

28. Ha W, Sevim-Nalkiran H, Zaman AM, Matsuda K, Khasraw M, Nowak AK, et al. Ibudilast sensitizes glioblastoma to temozolomide by targeting Macrophage Migration Inhibitory Factor (MIF). Sci Rep. 2019; 9: 2905. doi: 10.1038/s41598-019-39427-4

29. Chen X, Liao R, Li D, Sun J. Induced cancer stem cells generated by radiochemotherapy and their therapeutic implications. Oncotarget. 2017; 8: 17301-12.

30. Francis KR, Wei L. Human embryonic stem cell neural differentiation and enhanced cell survival promoted by hypoxic preconditioning. Cell Death Dis. 2010; 1: e22-11.

31. Khong TL, Thairu N, Larsen H, Dawson PM, Kiriakidis S, Paleolog EM. Identification of the angiogenic gene signature induced by EGF and hypoxia in colorectal cancer. BMC Cancer. 2013; 13: 518 doi: 10.1186/1471-2407-13-518.

32. Calvani M, Rapisarda A, Uranchimeg B, Shoemaker RH, Melillo G. Hypoxic induction of an HIF-1alpha-dependent bFGF autocrine loop drives angiogenesis in human endothelial cells. Blood. 2006; 107: 2705-12.

33. Shi YH, Wang YX, Bingle L, Gong LH, Heng WJ, Li Y, et al. In vitro study of HIF-1 activation and VEGF release by bFGF in the T47D breast cancer cell line under normoxic conditions: Involvement of PI-3K/Akt and MEK1/ERK pathways. J Pathol. 2005; 205: 530-6.

34. Han ZB, Ren H, Zhao H, Chi Y, Chen K, Zhou B, et al. Hypoxiainducible factor (HIF)- $1 \alpha$ directly enhances the transcriptional activity of stem cell factor (SCF) in response to hypoxia and epidermal growth factor (EGF). Carcinogenesis. 2008; 29: 185361. 